\title{
Saline intrusion on a coastal aquifer
}

\begin{abstract}
Saline intrusion represents one of the most persistent environmental problems at the worldwide coasts; this problem has arisen due to overexploitation of coastal aquifers, sea-level rise accelerated by climate change and changes on the hydrogeological cycle. Typically, changes on the hydrological cycle are associated to urbanization of recharge areas and changes on the natural surface and subsurface water bodies induced by anthropogenic interventions. Because of the accelerated growth of the population and the increased touristic activities this perturbation has called the attention of the scientific community and more recently of the decision makers. In the international context, one can find many efforts to define strategies to control and mitigate the effects of the saline intrusion on coastal aquifers, however at Colombia only some initiatives has been reported that intended to understand conceptually the phenomena. In this work, a numerical model is presented to simulate saline intrusion that allows understanding quantitatively the advance of the seawater into the aquifer. Such a model may serve as starting point towards the design of water management strategies at the Colombian coasts. In order to show the applicability of numerical models the Morrosquillo aquifer case is used. Different scenarios were studied using hypothetical conditions.
\end{abstract}

Keywords: saline intrusion, numerical modeling, colombian aquifers
Volume 2 Issue 5 - 2018

\author{
Vanessa Rodríguez Rueda,' Aníbal Pérez,' \\ Edgar Ricardo Monroy Vargas ${ }^{2}$ \\ 'Universidad Antonio Nariño, Colombia \\ Universidad Católica de Colombia, Colombia
}

Correspondence: Edgar Ricardo Monroy Vargas, Universidad Católica de Colombia, Colombia,

Email edgar-monroyl@unipiloto.edu.co

Received: July 17, 2018 | Published: September 21, 2018

\section{Introduction}

The exploitation of water resources has varied significantly throughout history. One of the practices that has increased its extraction is the use of underground wells located near the coasts, where, in some cases, freshwater aquifers are found. In the coasts, aquifers represent the main source of supply for their population, given their need, mainly in the industrial processes and the basic needs of the habitual population and the floating that comes permanently in the holiday season. The uptake of groundwater near coastal areas has in most cases grown without any control by the regional authorities. Particularly, in the Colombian context, there have been several problems for the community and the environment, the most notable being the contamination of coastal aquifers due to the presence of salts from the sea. ${ }^{1}$ The presence of these salts is due to the intrusion of the wedge of sea water, that is to say, due to the overexploitation of the mass of fresh water contained in a coastal aquifer, the sea water bursts in the continent to complete the balance that has Been interrupted by over-exploitation; Thus creating a mixing zone in which the salty and sweet waters are found, generating brackish waters that occupy a great extent of the aquifer. ${ }^{2}$ At present, one of the tools that could provide more detailed information about this phenomenon are the numerical models that allow the simulation of saline intrusion cases in different contexts. Thanks to these models, different hypothetical cases can be generated that would allow us to arrive at approximations close to reality that contribute to the knowledge of its state and to establish control measures. These impacts are the decrease in the quality of the coastal water due to the saline intrusion and other associated to the climatic change as: rise in the level of the sea, acidification of oceans, and change in the currents the ocean, coral bleaching and extreme changes in climate behavior.

\section{Saline intrusion case study}

Since the beginning of the twentieth century, tests were begun to determine mathematical models to assess the progress of possible contamination. One of the earliest examples is presented by Huyakorn et al., ${ }^{3}$ which focuses on developing a finite element model can simulate cases salt intrusion, for various cases of coastal geometry, including geomorphology variables and conditions particular aquifer (type). ${ }^{3}$ Bachu ${ }^{4}$ presented a review of methods applied to two case studies in which it is sought to estimate the variable density flux in the Albetc basin in Canada and the eastern plains in Colombia. From the piezometric levels, its location and the topography of the place, we tried to characterize the zones to start the construction of a model that allowed to simulate the behavior of the flow of variable density from the representation of a specific flow given by the flow and its speed. ${ }^{5}$ Zhou et al., ${ }^{6}$ present the simulation of the case progression of saline intrusion in the aquifer belonging to the Beihai coast off the coast of the Republic of China. From studies conducted from 1988 to 1993 has been evaluated the presence of salts along observation wells. The intrusion in the area is mainly attributed to the intensive extraction of groundwater near the coast without any regularization until 1988. For the summer of 1993 a decrease in the presence of chloride was observed due to the low extraction of water, product of a long period rains of that year. ${ }^{4,5}$

Monreal et al., ${ }^{7}$ studied the aquifer of the coast of Hermosillo, located in the sea of Cortes in the Pacific Ocean in the state of Sonora (Mexico). This coastal aquifer has been reducing its extraction: in 1965 about 1100 million $\mathrm{m} 3$ / year were extracted and in the decade of 2000 only 400 million $\mathrm{m}^{3} /$ year are extracted. In order to determine the progress of the salt water wedge, drilling of wells at different depths was proposed, as well as pumping tests, sampling, topographic surveys and electromagnetic geophysical surveys. From these field investigations a characterization of the study area was developed, which includes: geology (subsoil, soil, structural), geophysics, hydrogeology and hydro geochemistry. The field data collection allowed the definition of areas with intrusion problems, which an overall of $17 \mathrm{~km}$ in width and a length of $65 \mathrm{~km}$, with a resulting fringe of $1113 \mathrm{~km}^{2} .{ }^{7}$ Heredia et al., 
studied the case of sources of Pierre lagoon that is located in Malaga (Spain), approximately $50 \mathrm{~km}$ from the Alborán Sea. This wetland was one of the first to be included in the Ramsar Convention and is considered as one of the most important wetlands in Spain. It also represents a natural reserve that is of vital importance as the second largest flamingo reserve in the western Mediterranean. ${ }^{8}$ The objective of the study was to characterize the hydrogeological system of the zone from the application of hydrogeochemical techniques and the analysis of environmental isotopes. In special, the study included the analysis of the spatial distribution of groundwater salinity, flow tests, sampling for chemical and isotopic analyzes, and chemical analyzes of collected samples.

\section{Materials and methods}

In the present research the simulation of the phenomenon of saline intrusion in the Morrosquillo aquifer is proposed, which has an approximate area of $700 \mathrm{~km}^{2}$ and includes all the flat zone that extends from the western foothills of the Montes de Maria to some the coastline; And from the northern part of the hill system located in the municipalities of Coveñas and San Antonio dePalmito, to the south of the hill system associated with the municipality of San Onofre, ${ }^{9}$ as shown in Figure 1. The climate of the region is tropical dry forest. The average temperature of the area is $28^{\circ} \mathrm{C}$, the average annual rainfall is between 1100 and $1800 \mathrm{~mm}$. The value of the evapotranspiration calculated by the Penman method is more than $1000 \mathrm{~mm} .{ }^{10}$ The temporal distribution of precipitation occurs in mono modal form with a higher amount of rainfall between April and October. The lithology of the area is represented mainly by marine deposits near the coastline, fine alluviums and materials transported.

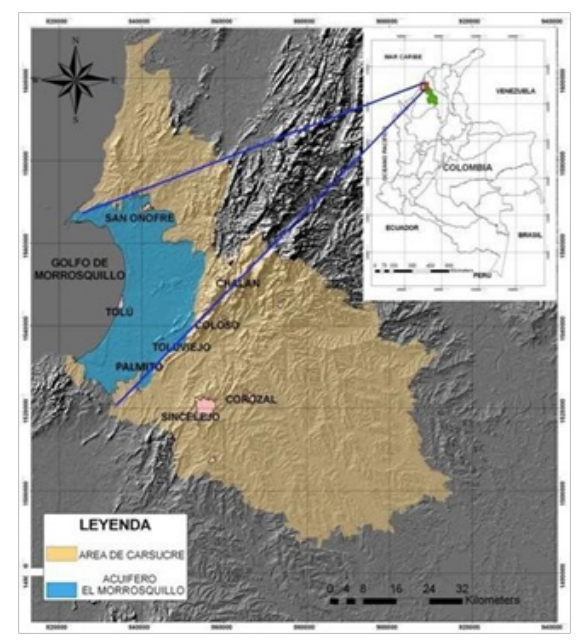

Figure I Morrosquillo aquifer, sucre (Colombia).

The Morrosquillo aquifer according to different studies carried out in the area presents important saline intrusion problems. In this study, an area located between the urban centers of the Tolú and Coveñas municipalities was chosen. The choice of the study area was based on the analysis of the results of monitoring campaigns Conducted in the Gulf of Morrosquillo, where potential problems of electrical conductivity were detected in the selected area. ${ }^{11}$ The computational model used to calculate the water flow is ModFlow ${ }^{12}$ while SEAWAT software is used for calculating variable density. These models were developed by the United States Geological Survey (USGS) and have been used extensively successfully in the literature in the simulation of saline intrusion cases and in general in variable density flow problems. In general, ModFlow is used to pair the velocity field and SEAWAT to calculate the concentration and the corresponding density. This is done in coupled mode for each time step.

\section{Simulation of scenarios}

To simulate scenarios mesh $1000 \mathrm{~m}$ long and $120 \mathrm{~m}$ coastal area with a mesh size of $5 \mathrm{~m}$ was constructed. A depth of $20 \mathrm{~m}$ was assumed. As initial condition for the distribution of concentrations it was assumed that the concentrations in the system $(\mathrm{Co}=0 \mathrm{mg} / \mathrm{L})$. In addition, values were assigned to the soil parameters obtained from typical cases in the literature, as summarized in the following Table 1. The boundary condition on the ocean side is defined as the constant level (Dirichlet boundary condition) and a salt concentration of $39,000 \mathrm{mg} / \mathrm{L}$ is assumed. The effects of climate change on sea level are associated with the thermal expansion of the oceans and the thawing of the planet's poles, so according to the intensity of these factors and their location they make more vulnerable places of the planet more vulnerable. Some authors have estimated that sea level increased $1.7 \mathrm{~mm} / \mathrm{yr}$ from 1860 to 1900 , while only from 1993 to 2003 its increase was $3.1 \mathrm{~mm} / \mathrm{yr} .{ }^{13}$ In order to incorporate the impact of climate change into this analysis, an estimate was made keeping the trend from 1993 to 2003 in the period between 2003 and $2015 .{ }^{14}$ On the other hand, 12 extraction wells were defined that serve to establish the extraction conditions for each scenario considered. In order to demonstrate the usefulness of the numerical models in the study of cases of saline intrusion in the Colombian context, three main scenarios are proposed, which are simulated for a period of 130 days.

Table I Values of the soil parameters chosen for the simulation

\begin{tabular}{ll}
\hline Property & Value \\
\hline Specific Storage & $1.0 \mathrm{e}-5 / \mathrm{m}$ \\
Specific performance & 0.2 \\
Effective porosity & 0.15 \\
Total Porosity & 0.3 \\
\hline
\end{tabular}

Base case: In this case only the effect of climate change is simulated in the study area and are not considered extractions.

Normal explotation: The study area is characterized by a tourist area in which a large number of people converge, where there are also several extraction wells established in the area (legal and illegal), which generates an exploitation of the resource Water for the normal satisfaction of their needs.

Overexploitation: For this scenario, the parameters established using the same location of the wells as in the previous case are continued. However, water extraction is increased in order to represent the overexploitation of the wells caused by the presence of a high floating population in the seasons of high tourist season. In that sense, in the model increases the exploitation levels in the wells according to the percentage values of increase in the demand of the water resource.

\section{Results}

Figures 2 \& Figure 3 show the concentration distributions for the cases used. The results show that for the scenario of the base case it is evident how the wedge advances the levels in the salt concentrations in a simulation of 130 days. From this perspective, the model is able to reproduce the effect of climate change, illustrating the advance of the 
pollution caused by the saline intrusion in the aquifer. The results for the case where a typical extraction of water through extraction wells in the region were assumed, shows the advance of the salt wedge through determined preferential paths due to the flow distributions imposed by the extraction wells. This distribution suggests that for normal exploitation scenarios with the growing problem of climate change the deterioration of the quality of the waters of the study area will increase.

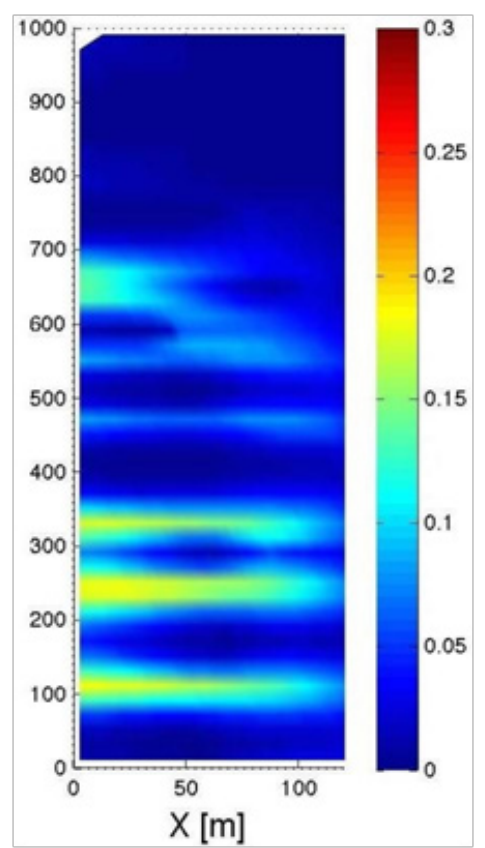

Figure 2 Distribution of salt concentrations in the study area for the case of normal exploitation.

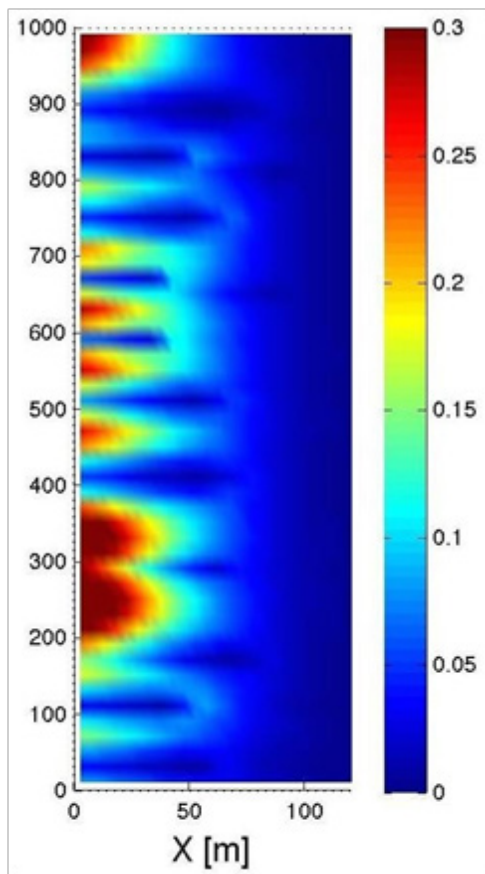

Finally, the results for the case of overexploitation during high season represented by an excessive extraction of water, show again an advance of the wedge through preferential paths. This results in an increase in the susceptibility of the wells to be affected by the saline intrusion and a consequent affectation of the quality of the extracted waters, which is used in various activities in the tourism infrastructure located in the municipalities of Tolú and Coveñas.

\section{Conclusion}

The determination of the saline water mass in a coastal aquifer is extremely complex due to the need for hydrogeological studies, as well as specific measurements of salinity levels at different points in the aquifer. In Colombia the presence of saline intrusion has not been evaluated effectively, first because it is still not seen as a type of contamination and second because there is no clear information about its presence or not. Therefore, given the lack of accurate information, few cases are known and studied about possible contamination by saline intrusion. In the present work, the Morrosquillo aquifer was modeled using the ModFlow and SEAWAT models to analyze the salt intrusion process. This modeling was done using soil parameter values taken from the literature and adapted to the properties of the area. For the analysis, three synthetic cases were implemented: base case, normal exploitation and overexploitation during a period of 130 days. The results of the simulations show that there could be great implications of the phenomenon in the Morrosquillo aquifer derived from the overexploitation associated to the tourist activity, especially in high seasons. The problem is aggravated by the lack of information associated with the hydrogeological characteristics of the aquifer, the absence of an exhaustive inventory of wells and their extraction flows, and the limited multitemporal information on the water quality conditions associated with the aquifer. In this sense, it is necessary to carry out descriptive studies of aquifers in coastal areas, to regulate the presence of extraction wells that allow a more reliable quantitative evaluation of the true magnitude of the phenomenon of saline intrusion in the Morrosquillo aquifer and in the majority of aquifers Coastal conditions in the Colombian context where the situation is not very different.

The processes of induced pollution through the overexploitation of coastal aquifers requires characteristic studies that involve field work (sampling and drilling) and the use of numerical models. Use a numerical model in the simulation of saline intrusion cases represents a tool with many potential in decision making since it allows not only the analysis of the current situation and understanding of the phenomenon but the evaluation of possible future scenarios that incorporate anthropogenic variables And natural resources such as climate change, population growth and tourism development. This could contribute definitively towards the design of sustainable strategies to mitigate and control the processes of saline intrusion.

\section{Acknowledgements}

None.

\section{Conflict of interest}

The author declares there is no conflict of interest.

Figure 3 Distribution of salt concentrations in the study area for the case of overexploitation. 


\section{References}

1. Herbert ER, Schubauer-Berigan J, Craft CB. Differential effects of chronic and acute simulated seawater intrusion on tidal freshwater marsh carbon cycling. Biogeochemistry. 2018;138(2):137-154.

2. Ruiz LB, Pulido Velázquez D, Renau Pruñonosa A, et al. An indexbased method to assess impacts of global change on seawater intrusion problems. In Groundwater and Global Change in the Western Mediterranean Area: Springer, Cham. 2018;19-26.

3. Huyakorn PS, Mercer JW, Ward DS. Finite Element Matrix and Mass Balance Computational Schemes for Transport in Variably Saturated Porous Media. Water Resources Research. 1985;21(3):346-358.

4. Bachu S. Flow of variable-density formation water in deep sloping aquifers: review of methods of representation with case studies. Journal of Hydrology. 1995;164:19-38.

5. Chang Y, Hu BX, Xu Z, et al. Numerical simulation of seawater intrusion to coastal aquifers and brine water/freshwater interaction in south coast of Laizhou Bay, China. Journal of Contaminant Hydrology. 2018;215-1-10.

6. Zhou X, Chen M, Ju X. Numerical simulation of sea water intrusion near Beihai, China. Environmental Geology. 2000;40(1-2):223-233.

7. Medina MR, Monreal R, Morales M, et al. Estimation of the vulnerability to saline intrusion of the coast of Hermosillo aquifer, Sonora, Mexico. Geofisica International. 2004;43(4):611-621.
8. Heredia J, Ruiz JM, Domingo A, et al. Caracterización de un sistema hidrogeológico complejo: Laguna de Fuente de Piedra. Boletín Geológico YMinero. 2009;120(3):423-442.

9. Mercado O. Recopilación y Organización de la Información Hidrogeológica del Acuífero de Morrosquillo (Sucre). Xonat Litoral Sur de Santiago de Tolú-Coveñas. Universidad deSucre. 2006;1-56.

10. Invemar. Formulación del Plan de Manejo Integrado de la Unidad Ambiental Costera Estuaria del Río Sinú y Golfo de Morrosquillo, Caribe colombiano. Informe Técnico Fase I- Caracterización y Diagnostico. 2002;802.

11. Hernández O. Recopilación y Organización de la Información Hidrogeológica del Acuífero Morrosquillo (Sucre). Zona litoral Norte Santiago de Tolú-San Onofre. Universidad de Sucre. 2006;1-49.

12. Langevin CD, Guo W. MODFLOW/MT3DMS-Based Simulation of Variable- Density Ground Water Flow and Transport. Groundwater. 2006;44(3):339-351.

13. Guo W, Langevin CD. User's guide to SEAWAT; a computer program for simulation of three-dimensional variable-density ground-water flow (No. 06-A7). USGS. 2002.

14. Bindoff NL, Willebrand J, Artale V, et al. Observations: oceanic climate change and sea level. Climate Change 2007: The Physical Science Basis. Contribution of Working Group I to the Fourth Assessment Report of the Intergovernmental Panel on Climate Change. 2007;1-48. 